\title{
Key Factors of an Organization's Environment for the Acquisition and Assimilation of an Innovation
}

\author{
Sanjana Buć \\ Institut IGH d.d. \\ Zagreb, Croatia
}

sanjana.buc@gmail.com

Blaženka Divjak

Faculty of Organization and Informatics

blazenka.divjak@foi.hr

University of Zagreb, Varaždin, Croatia

\begin{abstract}
The paper deals with influential factors of an organization's environment in the initial phase of diffusion of innovations (DOI) within the organization. A qualitative research was carried out with two expert groups: one for the diffusion of e-learning as an innovation in a higher education institution and the other for the diffusion of the Building Information Modelling (BIM) in a Construction Industry. The research disclosed 20 common factors. The internal environment group covers management support, the attitude towards innovation, strategic planning and communication, motivation and expertize of employers, available resources and IT maturity level of an organization. The group of business environment factors consists of competitors, clients and partners, supply and demand balance on the specific market for goods and services. In the social environment group, three factors are recognized on the national level and two on the global levels. The holistic model combines the theory of DOI and the concept of absorption capacity.
\end{abstract}

Keywords: e-learning, diffusion of innovations, absorptive capacity, higher education, BIM

\section{Introduction}

In this paper we consider the influence of organization's environment i.e. social system on ability of acquisition and assimilation of innovation in an organization. The goal is to compare results from two different systems: Architecture, Engineering and Construction (AEC) industry and higher education (HE). In this context we analysed the influence of environment factors on the diffusion of innovation: (a) elearning as an innovation in $\mathrm{HE}$ and (b) the Building Information Modelling (BIM) in an AEC industry.

Organizations in the system of higher education, especially faculties (colleges) and universities should fulfil a triple mission: to teach, do research and serve the society. In order to do it successfully, they must be innovative and strategically managed [1]. To accomplish their mission they have to satisfy three mutually 
contradictory requirements; to increase the number of students, improve quality and control costs [2]. Applying information and communication technology (ICT) not only in administrative processes was recognized as one of the crucial ways to satisfy these demands. There are various expressions used in literature to describe ICT support in learning depending on which element of e-learning is being stressed; from definitions which stress the technological aspect (technology-driven definitions) to the ones which recognize e-learning as a way to approach knowledge (deliverysystem-oriented definitions), from the ones which see it as a communication and interaction tool (communication-oriented definitions) to the definitions of e-learning as a way to improve the existing educational paradigm (educational-paradigmoriented definitions) [3].

We are going to use the definition of e-learning as proposed by Sangrà and coauthors in [3]:

"E-learning is an approach to teaching and learning, representing all or part of the educational model applied, that is based on the use of electronic media and devices as tools for improving access to training, communication and interaction and that facilitates the adoption of new ways of understanding and developing learning."

The panel of experts was consulted according to the modified Delphi process in order to draft Horizon report [4] where the impact of emerging technologies in colleges and universities across the globe is assessed on a five-year scale agreed on two long-term impact trends: advancing cultures of innovation, as well as to fundamentally rethink how universities and colleges work. That supports the main idea of this paper, connecting innovation and decision making process.

The Horizon panel recognized the technological developments that could support these drivers of innovation and change. Bring Your Own Device (BYOD), along with learning analytics and adaptive learning, are expected to be increasingly adopted by higher education institutions in one year's time or earlier. Further, augmented and virtual reality, along with makerspaces, is estimated to be implemented widely within two to three years, while affective computing and robotics are expected to be more prominent in colleges and universities within four to five years. However, e-learning is still not being adopted at the desired pace in Croatia although on global scale it is a very fast growing industry [4]. In order to examine this problem as thoroughly as possible, we can approach it from the position of adopting innovations. Here, Roger's theory of diffusion of innovation (DOI) can be useful [5].

On the other hand, the development of information and communication technology in construction industry resulted in Building Information Modelling (BIM) - the process of creation and use of data for the design, construction and use of building. There are many definitions of BIM [6], but all definitions have several key elements in common: the process of creating a digital model, combination of "smart" elements, which contain both qualitative and quantitative data, interoperability of data, integration of processes based on a high level of mutual cooperation of all stakeholders with a joint goal to manage the structure efficiently throughout its entire lifetime. The result of this process is a "building information 
model" - "a digital representation of physical and functional characteristics of a facility, a shared knowledge resource for information about a facility forming a reliable basis for decisions during its life-cycle" [7].

Despite the growing awareness of the benefits of using BIM throughout the life of a construction project, and even though the acceptance of BIM by organizations in Architecture, Engineering and Construction (AEC) industries has rapidly increased in recent years in fifteen of the world's leading economies, the general impression is that on a global level BIM is not being adopted as promptly as expected.

According to Murphy [8], this problem can be successfully solved if approached as implementation of innovation. Such approach was also supported by other authors, considering the factors of BIM diffusion [9], [10]. According to the Oslo Manual, BIM is both a product innovation and a process innovation [11]. According to the classification model [12], BIM is a systemic innovation since it requires changes in information and communication terms in different organizations, leading to complex problems of interoperability, and depending on the interconnectedness and cooperation of stakeholders as well as cultural changes, all aimed at creating a unique system in order to raise the quality of execution.

According to Rogers (2003), the author of DOI theory, the diffusion is "the process by which an innovation is communicated through certain channels over time among the members of a social system" [13]. The definition itself contains the four basic elements of diffusion of innovation: (1) innovation, (2) communication channels, (3) time and (4) social system. Therein, the innovation is "any idea, practice or object that is perceived as new by an individual or other unit of adoption. It matters little, as far as human behaviour is concerned, whether or not an idea is objectively new as measured by the lapse of time since its first use or discovery." [13].

In the first phase of the project called Development of a methodological framework for strategic decision-making in higher education - a case of open and distance learning implementation [14], the conceptual DOI model in higher education was set and the research about the impact of environmental factors of the organization in higher education on its capacity to adopt innovation was conducted on the sample of e-learning as innovation.

Similar conceptual model was used in investigating diffusion of BIM as an innovation in AEC organizations [6].

The results of the qualitative research described in this paper complement the results of previous studies contributing to the development of a model for the adoption of innovation in higher education organizations, as well as in AEC organizations.

\section{State of the art}

E-learning has been identified as one of the key resources in delivering quality and sustainable learning and, as an instance of ICT, it is an integral part of teaching and learning today. At the same time, it contributes to higher public status of an 
institution of higher education and development of digital skills of students, teachers and administrative staff. Urh et al. [15] write that "e-learning is being introduced as a fundamental part of the student learning experience in higher education". Divjak and Begičević [16] state that e-learning "supports skills needed in knowledge-based society and includes different teaching methods".

In the last ten years, a lot has been said and written about the critical success factors of adoption of e-learning in the HE [17], and various models of introducing e-learning in higher education have been developed [18].

Reviewing the literature on the topic of e-learning published between 2001 and 2013, Singh and Hardaker [9] summarize that published articles and research results on barriers and enablers to adoption and diffusion of e-learning were mainly focused on the importance of having an e-learning strategy; the role of social networks and social phenomenon of opinion leaders; top-down (which can become counterproductive) and bottom-up approaches to diffusion, the role of management, the importance of the administrative and technical infrastructure to support the adoption of e-learning, personal attitude towards innovation, demographic factors (age and gender), perceived time required for adoption of innovation, lack of mechanisms to control the implementation of e-learning.

It can be concluded that it is necessary to develop a theoretical framework to integrate the research into the influence of exogenous factors and the impact of individual strategies in a single model [9].

The research dealt with single segments related to BIM: definitions, elements, advantages and problems [19], [20], [21], [22]. Models were developed to evaluate the maturity of BIM being adopted by a certain organisation, international organisations were founded to strengthen global integration and mutual co-operation in the construction sector [7]. Research of the German AEC sector [23] showed that the main obstacles for the adoption of BIM at the technical level are - insufficiently supported implementation of IFC standards, at the level of standards - the need for higher quality standardization, and at the level of education - lack of new concepts of education and university (higher) education. However, for the users of BIM, the financial aspect was neither an obstacle nor a problem for its adoption. The Malaysian research [24] had a similar conclusion, whose results show that it is not the costs which are a key obstacle for BIM implementation, but the lack of expertise, training, and awareness about the need to introduce BIM. In the international research with leading BIM experts [25], the inter-organizational issues such as willingness to share information, master BIM model team/managers, effective collaboration between project participants, and organizational structure to support BIM were recognized as critical factors for the adoption of BIM. The changes in business processes necessary to adopt BIM are slow. Thus, special attention should be paid to motivating the management and employees [26]. Recent research has focused on the issues of trust among the participants in the construction project [27], [28], partnership [29], the culture of knowledge and the devotion of the top management of the organisation, as well as on the effective communication support as key factors of knowledge management between and within temporary organisations [30]. Further on, political influence has proved crucial for the adoption 
of new processes and technologies in construction industry. In Europe, for example, the governments of the developed countries are the main promotors of the adoption of BIM through the public projects they launch. [22].

Although electronic sources of different manuals on planning implementation of BIM are available, a comprehensive frame, which would holistically consider the process of BIM implementation as the diffusion of innovation together with key factors that influence this process of diffusion [6] has not been elaborated so far.

On the other hand, although the theory of diffusion of innovation was recognized as a valuable theoretical framework for examining the adoption of innovation by individual organizations, previous studies were less concerned with the process of diffusion and processes which affect the adoption of innovations and more with factors outside communication itself, such as attributes of innovation. The last presents one of the main objections and at the same time guidelines for further contribution to the development of the theory of diffusion of innovations [31].

\section{Research problems}

Conceptual model of the diffusion of innovation in the higher education system [32], as well as the conceptual model of BIM diffusion [6] defines two principle phases of the diffusion process of the organization: the initial phase (initiation) preceding the decision on the acceptance of innovation, and the implementation phase (implementation) following the positive decision on the acceptance of innovation.

While the results of previous studies regard both of specific elements of the diffusion process and e-learning, the innovation itself, the impact of the social system in the process of diffusion of this innovation is neither sufficiently considered, nor defined.

The conceptual model of diffusion of innovation is based on a theoretical model of diffusion of innovation, but it is also complemented by the basic postulates of the concept of absorptive capacity. The foundations of the concept of absorptive capacity (ACap) were set by Cohen and Levinthal who defined absorption capacity as "the ability of companies to recognize the value of new, external information (external knowledge), to assimilate it and apply it to their business results" (an ability to recognize the value of new information, assimilate it, and apply it to commercial ends) [33] and consider it a key factor in innovation capacity of enterprises.

Most cited contribution to the development of the theory of absorptive capacity is the work of Zahra and Goerg in 2002 which defined the absorption capacity (ACap) as " a set of organizational routines and processes by which firms acquire, assimilate, transform and exploit knowledge to produce a dynamic organizational capability" [34]. From the very definition follow four dimensions of ACap: acquisition, assimilation, transformation and exploitation. Under the "acquisition" the authors understand the ability of a company to identify and acquire external knowledge that is critical to its business. "Assimilation" refers to the routines and processes that allow companies to analyse, process, interpret and understand the information obtained from external sources. By "transformation" authors mean the 
ability of companies to develop and improve their processes by combining the existing knowledge with the newly acquired and assimilated knowledge. It is achieved by adding or deleting skills or simply interpreting the same knowledge in different ways. The fourth component, "exploitation", refers to the ability of the organization based on the processes that allow the organization to improve, expand and use the existing competences or to create new competencies by installing the adopted and transformed knowledge into its business. The authors further categorized the four dimensions of ACap into two ACap components; a "potential ACap" consists of acquisition and assimilation, whereas the transformation and exploitation are components of a "realized ACap".

The research, whose description and results are shown below, was carried out in order to give answers to two research questions:

- What are the common most influential environmental factors of: (a) an organization in higher education (a faculty) and (b) an AEC organization which affect the capacities of those organizations in Croatia for the acquisition and assimilation of innovation (on an example of e-learning and BIM)?

- How can the DOI model be applied to problems of diffusion of innovations (a) in HE, especially in the adoption of e-learning at the faculty, and (b) in construction industry in the adoption of BIM?

To answer these questions, a qualitative research was conducted and is described in detail in this paper.

\section{Research methodology}

In order to investigate the influence of the social system, that is to say of the environment of the organization on its ability to absorb and acquire innovation, a qualitative research was carried out to define the measuring instrument for the key factors of this particular environment for the recognition and acceptance of an innovation in organizations in Croatia. In the development of instruments, the examples of the development of instruments were used that are specific to research in information sciences, such as the development of a measuring instrument for assessing the performance of ePortfolio [35].

\subsection{Creating initial set of items}

To create an initial set of items for the purposes of this research, the starting point is the theoretical conceptual definition of the environment. According to Buble [36], "environment means the totality of the factors that affect the company's business which must be respected by the management when making decisions." There is external environment and internal environment. Additionally, [36] stated that external environment includes those segments of the environment which indirectly affect the company/organization. Buble further divides the external environment into the general or social environment and the business environment or the environment of the task. The main feature of general or social environment (macro-environment) is that it is not under the direct control of the company/organization. Business 
environment or the environment of the task (micro-environment) "is made of factors in the immediate environment of the company/organization which affect its ability to serve this environment." [36]. Internal (indoor) environment "represents that part of the total environment of the company, which is located inside it." It can be fully managed and influenced [36].

Initial set (initial pool) of items consisted, therefore, of three main groups of environmental factors and their sub-groups (e.g. a group of factors of internal environment consisted of subgroups: organizational structure, organizational culture and resources), and in each of these subgroups, as a result of completion of the literature review, individual factors were associated. Although it is not possible to determine the exact number of items which the initial set should contain, the general rule is, the higher the initial set, the better it is, so it is not surprising that the initial set includes three to four times more items than the final scale, that is to say it should not be smaller than $50 \%$ of the final scale [37].

The initial set of items for the purposes of this study consisted of 22 items in the group of social environment factors, 12 items in the group of business environment factors and 39 items in the group of internal environment factors- in total of 73 items.

The results of pre-testing held in Higher Decision project workshop, 9th-11th July 2015 at the Faculty of Organization and Informatics, University of Zagreb (details in [32]), recognized 46 factors important for the development of the instrument grouped in tree basic groups: social, business and internal environment. These factors were used in the second research phase where domain specific experts separately judged their importance for specific innovation.

\subsection{Testing the content and the construct validity of environmental factors}

In the next step of the study, responses of experts both in e-learning and BIM, were collected through questionnaires which had been delivered to them by e-mail. In this way we tried to ensure the content validity of the instrument. In addition to the questionnaire, the respondents were submitted a letter explaining the objectives and ways of completing the questionnaire. First panel of experts (for e-learning innovation) involved in this phase of the study consisted of 10 experts in the field of e-learning (details in [32]). The second - Expert panel for BIM consisted again of 10 experts: four university professors from the AEC fields, four experts employed in the AEC organizations and two experts from organizations that provide BIM related software.

The questionnaire was developed in the form of MS Excel spreadsheet, and included 46 environmental factors of the organization. Respondents were supposed to determine the importance of each factor for the acquisition and assimilation of an innovation by selecting one of the answers ( 1 not a relevant factor; 2 important but not critical; 3 important; 0 cannot give an answer). In addition, they could make comments for each of the factors as additional detailed observation with regard to its relevance, clarity of description, etc. 
Lawshe's formula was used (content validity ratio, CVR) for the validation of content:

$$
C V R=\frac{(n-N / 2)}{N / 2}
$$

where $N$ is the total number of responses, $n$ is the frequency of panellists who evaluated the item with 2 or 3 (a positive response to the assessment of the impact of a certain environmental factor). The minimum value of CVR coefficient for 10 respondents was 0,62 [38]. After the analysis has been completed, it can be concluded that 36 items passed the CVR test.

In the questionnaire the panellists were also asked to classify each of the listed environmental factors in one of the groups: SE - General or social environment of the organization, BE - Business environment of the organization, IE - Internal (indoor) environment of the organization and $\mathrm{O}$ - Other (factor not appropriate for any of the listed groups of environmental factors). Although respondents categorized all the offered factors, only those factors were included in the analysis of construct validity of the instrument which had passed the previous CVR test.

The result of sorting environmental factors by e-learning group is shown in Table 1. The calculated Cohen's kappa coefficient was 0,62 which shows good agreement of experts of this research with the classification factor according to theoretical divisions and the results of previous research in accordance with the conducted analysis of literature. If an item has consistently been assigned to a specific category, it is considered that it has the validity of convergence with the particular construct and discriminant validity with the others.

In this case, with 36 items which passed CVR test, the judges (the panellists) have agreed on 27 items in total, divided into three main groups: 16 factors of internal environment, 6 business environment factors and 5 factors of social environment.

\begin{tabular}{|c|c|c|c|c|}
\hline $\begin{array}{c}\text { GROUP OF ENVIRONMENTAL } \\
\text { FACTORS }\end{array}$ & Initially & $\begin{array}{c}\text { After } \\
\text { CVR }\end{array}$ & $\begin{array}{c}\text { After } \\
\text { sorting }\end{array}$ & $\begin{array}{c}\text { After } \\
\text { qualitative } \\
\text { analyses }\end{array}$ \\
\hline INTERNAL ENVIRONMENT (IE) & 21 & 17 & 16 & 16 \\
\hline BUSINESS ENVIRONMENT (BE) & 13 & 9 & 6 & 6 \\
\hline SOCIAL ENVIRONMENT (SE) & 12 & 10 & 5 & 5 \\
\hline total & $\mathbf{4 6}$ & $\mathbf{3 6}$ & $\mathbf{2 7}$ & $\mathbf{2 7}$ \\
\hline
\end{tabular}

Table 1. Results of research of environmental factors for e-learning

After analysing BIM expert panel responses, a total of 29 items passed CVR test. After sorting environmental factors per groups, total of 26 items remained (Table 2). The calculated Cohen's kappa coefficient is 0,72, which shows good agreement of experts participating in this research with the classification factor according to theoretical divisions and results of previous researches in accordance with the literature. 
The panellists have agreed on 11 factors of internal environment, 9 business environment factors and 6 factors of social environment.

\begin{tabular}{|c|c|c|c|c|}
\hline $\begin{array}{c}\text { GROUP OF ENVIRONMENTAL } \\
\text { FACTORS }\end{array}$ & Initially & $\begin{array}{c}\text { After } \\
\text { CVR }\end{array}$ & $\begin{array}{c}\text { After } \\
\text { sorting }\end{array}$ & $\begin{array}{c}\text { After } \\
\text { qualitative } \\
\text { analyses }\end{array}$ \\
\hline INTERNAL ENVIRONMENT (IE) & 21 & 12 & 11 & 12 \\
\hline BUSINESS ENVIRONMENT (BE) & 13 & 10 & 9 & 10 \\
\hline SOCIAL ENVIRONMENT (SE) & 12 & 7 & 6 & 6 \\
\hline total & $\mathbf{4 6}$ & $\mathbf{2 9}$ & $\mathbf{2 6}$ & $\mathbf{2 8}$ \\
\hline
\end{tabular}

Table 2 Results of research of environmental factors for BIM

It can be seen that the total number factors is very close for both case studies (27 for e-learning in $\mathrm{HE}$ and 28 for BIM in AEC).

\subsection{Qualitative analysis and discussion of research results}

Final qualitative analysis of previously sorted environmental factors influencing the ability of a faculty to acquire and assimilate innovation in the case of e-learning was conducted by two experts. The final distribution of environmental factors after the completion of the qualitative analysis is shown in Table 1.

Qualitative analysis has proven that it is necessary to reformulate one factor. Another factor, which was initially placed in a group of social environment, should be transferred to the group of business environment, and two similar factors from the business environment should be merged into one. Therefore, the business environment group gets one more factor, but the total number remains the same. A group of social environment factors remains unchanged.

Some of these environmental factors were identified in the model Begičević et al as significant direct criteria for the decision on the selection of the appropriate method of application of e-learning in colleges [18]: human resources, ICT infrastructure for e-learning, or, indirectly through strategic readiness criteria, or legal and formal readiness for e-learning implementation. However, this model does not include external environment factors as criteria for the decision on e-learning implementation. External environmental factors, such as the influence of the size and structure of the market - via seller behaviour and via buyer behaviour - as well as common regulatory environment, which may be a slowing factor in some cases and accelerating in mandating a particular technological standard, and which may affect a decision on the adoption of innovation, have nevertheless been recognized in some other models of diffusion of innovation [39].

In the group of factors of internal faculty environment there are subgroups related to management support, attitude and expertise; training and motivation of employees; flexibility of key processes; availability of infrastructure and funding as well as organizational culture. 
Among factors of business environment the following subgroups can be recognized: needs of students and labour market; pressure by competitors and cooperation with partners on common projects. Factors of business environment cannot be straightforwardly transferred to higher education because customer-based HE service, originated from US-UK context, is not accepted in continental Europe. However new EU policy documents adopted after 2010 put special stress on the development of employability in HE. It is noticeable within the Europe 2020 strategy [40] called A Digital Agenda for Europe [41], whose main aim is to define the key role that ICT will play in the upcoming decade if Europe wants to succeed. A Digital Agenda for Europe is supported by the Agenda for new skills and jobs [42] and A New Skills Agenda for Europe [43], which are focused on supporting activities aimed at stimulating initiatives for employability of graduates.

In the group of factors of social environment there is a very strong subgroup of factors related to the role of the government in supporting innovation and quality standards development. Finally, factors of globalization and fast technology change are listed in that group.

Further review of comments of BIM panel respondents and qualitative analysis of other factors provided a list of 28 environmental factors of the AEC organization that affect its acquisition and assimilation of BIM (Table 2). Experts have identified twelve factors of internal environment relating to the role of management, strategic planning processes, formalization and communication within the organization, the importance of availability, expertise and motivation of employees and the availability of resources: ICT, financial and time. Maturity BIM models developed so far [44] mainly recognized four main groups of influencing factors: technology, process, people and information management.

Succar and his associates [45] analysed the problem of diffusion of BIM as mutually overlapping impact of nine "BIM player groups (stakeholders)": policy makers, educational institutions, construction organizations, individual practitioners, technology developers, technology service providers, industry associations, communities of practice, and technology advocates. The significance of these groups of factors was confirmed by the expert group for BIM. In the group of factors the business environment experts have recognized the impact of competitors, but also the support of partners in joint projects and the willingness of partners to adopt new knowledge and technologies; then suppliers of software, equipment and services, their support and presence in the market; support of professional associations and institutions; but also the demands and needs of clients and the size of the market demand.

Further, within the factors of social environment, the expert group for BIM gave great importance to the group of factors related to the government such as the government's development policies, legislation and its direct pressure through the specific requirements for the implementation of BIM in public projects that affects the organizational capacity for acquisition and assimilation of BIM. These factors are consequently related to other recognized social factors: the impact of economic recession, globalization of the construction industry and the intensity of technological change in the sector. In highly developed countries of the EU, there is 
an initiative to bring together national initiatives into a common European approach and aligned to develop a world-class digital construction sector [46]. According to Matthews, the Chairman of the EU BIM Task Group [46], "Europe is now host to the greatest regional concentration of government-led BIM programs in the world." There are three main reasons why the governments of the EU are interested to establish such an innovative way of work: (1) reduction in public spending or budget constraints, while (2) the need to build national infrastructure as a basis for growth and development, and (3) reducing consumption of natural resources and higher standards of sustainability.

\subsection{Comparative analysis of environmental factors}

Comparative analysis of research results on key influential factors of an organization's environment for diffusion of innovation for two case studies (for elearning in HE and BIM in AEC) is given in Table 3.

\begin{tabular}{|c|c|c|c|}
\hline IE & \multicolumn{2}{|c|}{ e-learning } & \multirow{2}{*}{ TOTAL } \\
\hline BIM & Imp & Not Imp & \\
\hline Important & 12 & 0 & 12 \\
\hline Not Important & 4 & 5 & 9 \\
\hline total & 16 & 5 & 21 \\
\hline Agreement & 12 & 5 & 17 \\
\hline By Chance & 9,14 & 2,14 & 11,29 \\
\hline Cohen's kappa: & 0,59 & & \\
\hline $\mathbf{B E}$ & \multicolumn{2}{|c|}{ e-learning } & \multirow{2}{*}{ TOTAL } \\
\hline BIM & Imp & Not Imp & \\
\hline Important & 5 & 5 & 10 \\
\hline Not Important & 0 & 3 & 3 \\
\hline total & 5 & 8 & 13 \\
\hline Agreement & 5 & 3 & 8 \\
\hline By Chance & 3,85 & 1,85 & 5,69 \\
\hline Cohen's kappa: & \multicolumn{3}{|l|}{0,32} \\
\hline SE & \multicolumn{2}{|c|}{ e-learning } & \multirow{2}{*}{ TOTAL } \\
\hline BIM & Imp & Not Imp & \\
\hline Important & 3 & 3 & 6 \\
\hline Not Important & 2 & 4 & 6 \\
\hline total & 5 & 7 & 12 \\
\hline Agreement & 3 & 4 & 7 \\
\hline By Chance & 2,50 & 3,50 & 6,00 \\
\hline Cohen's kappa: & \multicolumn{3}{|l|}{0,17} \\
\hline
\end{tabular}

Table 3 Comparative analysis of environmental factors

Both groups of experts recognized 12 common factors (out of 12 for BIM and 16 for e-learning) in the group of internal organization environment with Cohen kappa coefficient 0,59 . We found less agreement concerning the group of factors of business environment where there are 5 common factors (out of 10 for BIM and 5 
for e-learning) with Cohen kappa of 0,32. Finally, a low level of agreement with Cohen kappa of 0,17 is for the group of factors of social environment with only 3 shared factors (out of 6 for BIM and 5 for e-learning) for both case studies.

\section{Discussion of results}

The comparative analysis of research results of the environmental influential factors of the organization on the acquisition and assimilation of innovation in the example of e-learning at faculty and BIM in AEC organization has shown that 20 environmental factors can be recognized as common important influential factors for the acceptance of innovation in organization (Table 4).

\begin{tabular}{|c|c|}
\hline \multicolumn{2}{|c|}{ FACTORS OF INTERNAL ENVIRONMENT } \\
\hline IE02 & Support of senior management at the organizational level \\
\hline IE03 & Level of IT expertise of the employees \\
\hline IE04 & Level of IT infrastructure of the organization \\
\hline IE05 & Pro-innovative attitude of the management of an organization \\
\hline IE06 & $\begin{array}{l}\text { Available funds that the organization intended for IT infrastructure, training of } \\
\text { employees to adopt new knowledge and technologies and further research and } \\
\text { development }\end{array}$ \\
\hline IE08 & $\begin{array}{l}\text { Formalization of the rules, procedures and communication channels at the organization } \\
\text { level }\end{array}$ \\
\hline IE09 & $\begin{array}{l}\text { Availability of human resources with the necessary knowledge and skills within the } \\
\text { organization }\end{array}$ \\
\hline IE10 & $\begin{array}{l}\text { Strategic planning of the adoption of new technologies and innovations in the } \\
\text { organization }\end{array}$ \\
\hline IE11 & Systematic training of employees of the organization \\
\hline IE14 & Attitude and motivation of employees towards changes and lifelong learning \\
\hline IE15 & Available time within the organization for acquiring new knowledge and technologies \\
\hline IE16 & Communication within the organization (formal and informal) \\
\hline \multicolumn{2}{|r|}{ FACTORS OF BUSINESS ENVIRONMENT OF THE ORGANIZATION } \\
\hline BE01 & Pressure by competitors at national and EU level to accept innovation \\
\hline BE04 & Needs of the client and project partners to implement an innovation \\
\hline BE06 & $\begin{array}{l}\text { Requirements of the market - the need for qualified staff educated at the college / for } \\
\text { implementation of BIM }\end{array}$ \\
\hline BE07 & Availability and support of suppliers of ICT software, equipment and services \\
\hline BE09 & $\begin{array}{l}\text { Support of partners who work with teams from the organization on joint projects } \\
\text { involving ICT }\end{array}$ \\
\hline \multicolumn{2}{|r|}{ FACTORS OF SOCIAL ENVIRONMENT } \\
\hline SE04 & $\begin{array}{l}\text { Pressure by the government to set standards with requirements for the implementation } \\
\text { of an innovation }\end{array}$ \\
\hline SE07 & Globalization \\
\hline SE10 & Intensity of technological change \\
\hline
\end{tabular}

Table 4 Common environmental factors for acquisition and assimilation of elearning in $\mathrm{HE}$ and for BIM in AEC 
In the group of factors of internal environment, which is the largest one, we can recognize several subgroups: the first one related to the management support, the attitude towards an innovation, strategic planning and communication, the second one related to the motivation and expertize of employers, the third one connected to the available resources in form of funding, infrastructure, and training and finally, one connected to IT maturity level of an organization. Further research should be done to better recognize if the IT maturity level is an invariant in that group of factors.

The group of business environment factors is rather straightforward because there are factors related to well-known elements of market completion: competitors, clients and partners, as well as supply and demand balance on specific market for goods and services.

There are three common factors in social environment group: one on national level (governments which introduce and propose standards) and two global ones related to technological development and the influence of globalization on the sector in general.

There are several limitations of this research. The first is related to the specifics of organizations and their environment in Croatia. Then, the survey was conducted taking into account just the first phase of the developed DOI model. Finally, we used two small expert groups and therefore a factor analysis was not possible. In further research it can help describe factors more clearly and without redundancies but then the bigger sample of respondents will be needed.

\section{DOI model}

The analysis of previous studies of diffusion of innovation at the level of an organization and the results of the qualitative research have shown that the initial conceptual model of diffusion of innovations in HE [32] and the conceptual model of BIM diffusion in AEC organizations [6] can be upgraded in the model shown in Fig. 1 .

The process of diffusion of innovation through an organization starts by raising awareness of the need to adopt the innovation. This need can follow from the necessity such as participation in a project with foreign partners, or to occupy or keep the existing position on the market, i.e. the conservation of competitiveness or owing to the growing need of a stakeholder for the application of the innovation.

In order for the management of the organization to decide about introducing the innovation, it is necessary to perform the analysis of business opportunities and risks which follow after the decision on adoption or decision on non-adoption of innovation, as well as cost estimate, to provide required resources (finances, people, space, information and communication equipment, required licenses etc.). The team, a work group for strategic planning, prepares the strategic plan for adoption of innovation, and the top management of the organization, or another decision making body, adopts it and reaches a decision to move on to the implementation phase. Therefore, the team shall include members of the organization with different 
authorities and responsibilities, from persons that have the possibility to lead this process throughout the organization, decision makers that are authorized to provide required resources, persons that will be able to monitor the progress of the process and manage the changes in the process, to persons that might be directly impacted by the innovation adoption, motivated persons that might contribute to the process.

After reaching the decision on innovation adoption, it is necessary to prepare a detailed action plan for its implementation. It shall include all the required adjustments/changes of the existing work processes, starting from the innovation implementation on a selected pilot project by the team designated for the implementation, then training and providing user support for a wider use through continuous work with the innovation as a widely accepted method of work in an organization, and the assessment of what was achieved and finding new ways and means to improve the entire work process (Fig. 1).

It is important to monitor the implementation process very closely and to adopt the action plan continuously. The process itself is affected not only by the previously acquired relevant knowledge and the perceived characteristics of innovation, but also by the factors of social and external business environment, as well as the factors of internal environment in a particular organization.

Limitations of this research are connected to the limitations of a research with specific domain expert groups as they are described in [6] and [32]. Further, for finding common factors for the influence of environment of an organization on diffusion of an innovation in general the sample used here is still too small because other types of organizations, different innovations as well as other countries and regions can indicate some new key factors. Therefore, the absorption capacity for innovation should be complemented by enabling capacity for creation of innovation.

Further research needs to be done in other application environments, types of organizations and innovations.

\section{Conclusion}

The intention is to build a model of diffusion of innovation holistically. The very process of adoption of innovations at the organizational level according to Rogers' theory of diffusion of innovation has been complemented by the final phase "Evaluation and improvements", the phase in which the usefulness of the adopted innovation is assessed, and at the same time its improvements, i.e. starting of the new innovation cycle is made possible.

The social system influences the process of diffusion of innovation through three basic levels: the social environment, the business environment and the internal environment of the organization, and this during the whole cycle of diffusion of innovation, which takes some time.

The time required for the initial part of the process, before making a decision on the adoption of innovations depends on the potential absorption capacity of the organization to accept innovation, while the implementation phase is under the influence of an implementation of the absorption capacity of the organization to adopt the innovation. 


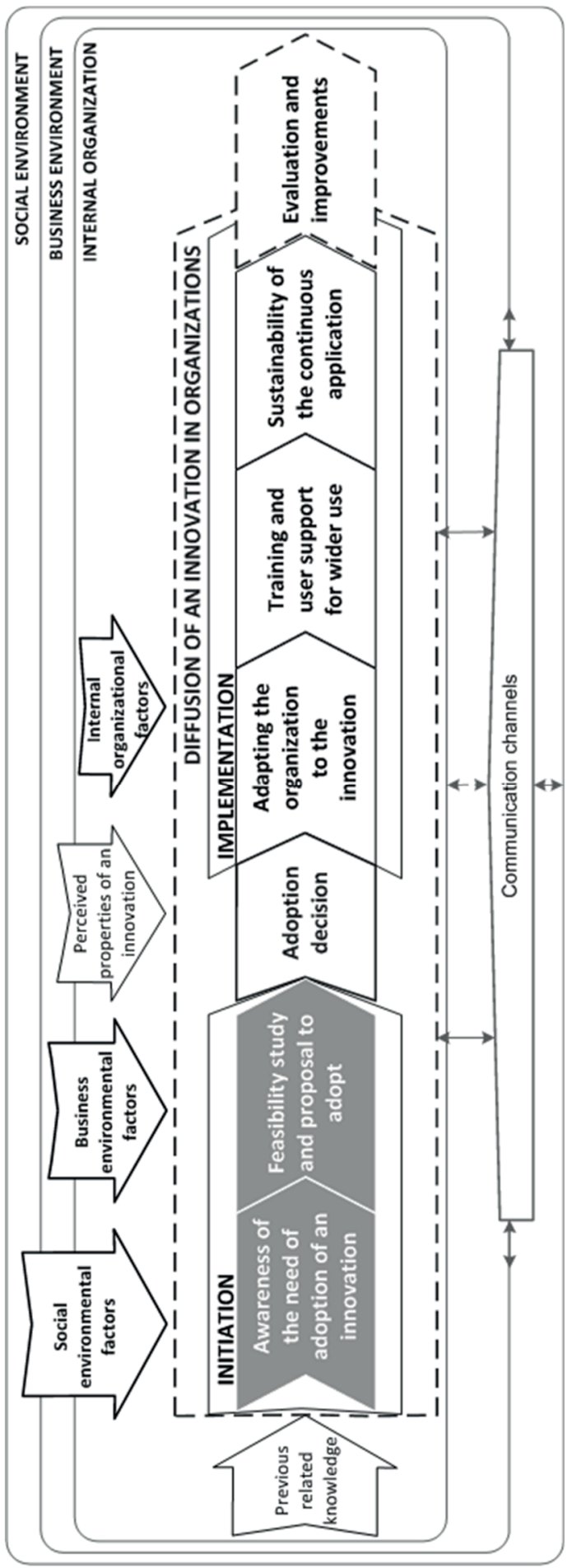

Figure 1. DOI model 
The research, which is described in this paper, identifies environmental factors, and social systems that affect the potential absorptive capacity of the organization to adopt innovation based on the case of the adoption of e-learning by universities and faculties in Croatia, as well as the adoption of BIM by AEC organization.

Such upgrading of diffusion of innovation models with the concept of absorptive capacity provided scientific contribution to the further development of these theories.

Here 20 environmental factors were recognized as common important influential factors for the acceptance of innovation in an organization divided in three groups related to internal, business and social environment of an organization. The richest and the most interesting results are obtained for the group of factors of internal environment which can be a decisive factor for the introduction of innovation. This group covers management support, the attitude towards an innovation, strategic planning and communication, motivation and expertize of employers, available resources and IT maturity level of an organization. The group of business environment factors consists of well-known elements of market completion: competitors, clients and partners, as well as supply and demand balance on a specific market for goods and services. In the social environment group, three levels are recognized on a national level and two global levels related to technological development and the influence of globalization on the sector in general.

Further research on inner innovation process should be performed. Additionally, future research should show which capacities an organization needs to have in order to implement innovation, not just to adopt it. The last recommendation for further research is directed towards assessment if the factors identified here are transferable to other innovations within HE system or AEC organizations.

\section{Acknowledgements}

This work has been partly supported by Croatian Science Foundation under the project Higher Decision IP-2014-09-7854.

\section{Appendix A: Environmental factors of faculties for acquisition and assimilation of e-learning}

\begin{tabular}{|l|l|}
\hline FACTORS OF INTERNAL FACULTY ENVIRONMENT \\
\hline IE02 & Support of senior management at the faculty level \\
\hline IE03 & Level of IT expertise of the employees of the Faculty \\
\hline IE04 & Level of IT infrastructure at the Faculty \\
\hline IE05 & Pro-innovative attitude of the Faculty management \\
\hline IE06 & Faculty funds available for R \& D \\
\hline IE08 & Formalization of the rules, procedures and communication channels at the Faculty \\
\hline IE09 & Availability of human resources with the necessary knowledge and skills within the Faculty \\
\hline
\end{tabular}




\begin{tabular}{|l|l|}
\hline IE10 & Strategic planning of the adoption of new technologies and innovations at the Faculty \\
\hline IE11 & Systematic training of the employees at the Faculty \\
\hline IE13 & Extent of education of the top management at the Faculty \\
\hline IE14 & Attitude and motivation of employees towards changes and lifelong learning \\
\hline IE15 & Time available for the acquisition of new knowledge and technologies at the Faculty \\
\hline IE16 & Communication at the Faculty (formal and informal) \\
\hline IE19 & Exchange of knowledge as part of the work process \\
\hline IO20 & Organizational culture at the Faculty which encourages innovation \\
\hline IO21 & Culture of mutual trust and cooperation at the Faculty \\
\hline FACTORS OF BUSINESS ENVIRONMENT OF THE FACULTY \\
\hline BE01 & Pressure of competitors in higher education and research \\
\hline BE04 & Needs of the client, i.e. students and project partners to implement e-learning \\
\hline BE06 & Requirements of the labour market - the need for qualified staff educated at a college \\
\hline BE07 & Availability and support of suppliers of ICT software, equipment and services \\
\hline BE09 & Support of partners who work with teams from the Faculty on joint projects involving ICT \\
\hline SE06 & Cooperation with foreign partners in the research, educational and development projects \\
\hline FACTORS OF SOCIAL FACULTY ENVIRONMENT \\
\hline SE02 & $\begin{array}{l}\text { Government support for innovation through the adoption of regulations and incentives for } \\
\text { innovation }\end{array}$ \\
\hline SE04 & $\begin{array}{l}\text { Pressure of the government to set standards in the higher education system with } \\
\text { requirements for the implementation of e-learning }\end{array}$ \\
\hline SE07 & Globalization of higher education and research \\
\hline SE10 & Intensity of technological change \\
\hline
\end{tabular}

\section{Appendix B: Environmental factors of AEC organization for acquisition and assimilation of BIM}

\begin{tabular}{|c|c|}
\hline \multicolumn{2}{|r|}{ FACTORS OF INTERNAL FACULTY ENVIRONMENT } \\
\hline IE02 & Support of senior management at the level of an organization \\
\hline IE03 & Level of IT expertise of the employees \\
\hline IE04 & Level of IT infrastructure of the organization \\
\hline IE05 & Standpoint of the organization management on competition \\
\hline IE06 & $\begin{array}{l}\text { Available funds that the organization intended for the procurement and maintenance of IT } \\
\text { infrastructure and training of employees to adopt new knowledge and technologies }\end{array}$ \\
\hline IE08 & Formalization of rules, procedures and communication channels at the organization level \\
\hline IE09 & $\begin{array}{l}\text { Availability of human resources with the necessary knowledge and skills within the } \\
\text { organization }\end{array}$ \\
\hline IE10 & $\begin{array}{l}\text { Strategic planning of the adoption of new technologies and innovations at the organization } \\
\text { level }\end{array}$ \\
\hline IE11 & Systematic training of the organization employees \\
\hline IE14 & Attitude and motivation of employees towards changes and lifelong learning \\
\hline IE15 & Available time within the organization for acquiring new knowledge and technologies \\
\hline
\end{tabular}




\begin{tabular}{|c|c|}
\hline IE16 & Communication within the organization (formal and informal) \\
\hline \multicolumn{2}{|r|}{ FACTORS OF BUSINESS ENVIRONMENT OF THE FACULTY } \\
\hline BE01 & Pressure of competition at national and EU level to accept innovation \\
\hline BE03 & Pressure of the construction sector at national and EU level to accept innovation \\
\hline BE04 & Needs of the client, investors / the final beneficiaries to implement BIM \\
\hline BE05 & Level of market demand for a given innovation \\
\hline BE06 & Requirements of customers / clients and project partners, for the implementation of BIM \\
\hline BE07 & Availability and support of suppliers of ICT software, equipment and services \\
\hline BE08 & $\begin{array}{l}\text { Number and availability of suppliers of software, equipment and services related to the } \\
\text { implementation of BIM }\end{array}$ \\
\hline BE09 & $\begin{array}{l}\text { Support of partners who work with teams from the organization on joint projects involving } \\
\text { ICT }\end{array}$ \\
\hline BE10 & $\begin{array}{l}\text { Willingness of partners who collaborate with the organization for the adoption of new } \\
\text { knowledge and technologies }\end{array}$ \\
\hline BE12 & Support of professional associations and institutions \\
\hline \multicolumn{2}{|c|}{ FACTORS OF SOCIAL FACULTY ENVIRONMENT } \\
\hline SE01 & Legislation through general and specific laws and technical requirements \\
\hline SE03 & $\begin{array}{l}\text { The government's policy in favour of strengthening the capacity to adopt innovations in the } \\
\text { economy }\end{array}$ \\
\hline SE04 & $\begin{array}{l}\text { Pressure of the government to set standards in the higher education system with } \\
\text { requirements for the implementation of BIM }\end{array}$ \\
\hline SE05 & Economic recession affecting the construction sector \\
\hline SE07 & Globalization of the construction industry \\
\hline SE10 & Intensity of technological change \\
\hline
\end{tabular}

\section{References}

[1] B. Divjak and N. Begičević Ređep, "Strategic Decision Making Cycle in Higher Education: Case Study of E-learning," in Proceeding of the International Conference on E-learning 2015, Las Palmas, Spain, 2015.

[2] T. Bates and A. Sangra, Managing Technology in Higher Education: Strategies for Transforming Teaching and Learning, San Francisco: JosseyBass/John Wiley \& Co, 2011.

[3] A. Sangrà, D. Vlachopoulos and N. Cabrer, "Building an inclusive definition of e-learning: An approach to the conceptual framework," The International Review of Research in Open and Distributed Learning, vol. 13 , no. 2, pp. 145-159, 2012 ..

[4] L. Johnson, S. Adams Becker, M. Cummins, V. Estrada, A. Freeman and C. Hall, "NMC Horizon Report: 2016 Higher Education Edition," The New Media Consortium, Austin, Texas, 2016.

[5] A. Gonçalves and N. Pedro, "Innovation, e-Learning and Higher Education: An Example of a University' LMS Adoption Process" World 
Academy of Science, Engineering and Technology, vol. 6, no. 6, p. 258$265,2012$.

[6] S. Buć, "Diffusion of Building Information Modelling as an Innovation: A Conceptual Framework for Research," in 12th International Conference Organization, Technology and Management in Construction, Primošten, 2015.

[7] BuildingSmart, www.buildingsmart.org/standards/technical-vision, [Accessed 15. jun 2015.]

[8] M. Murphy, "Implementing innovation: a stakeholder competency-based approach for BIM," Construction Innovation, vol. 14, no. 4, pp. 433-452, 2014.

[9] G. Singh and G. Hardaker, "Barriers and enablers to adoption and diffusion of eLearning.A systematic review of the literature - a need," Education+ Training, vol. 56, no. 2/3, pp. 105-121, 2014.

[10] K. Panuwatwanich and V. Peansupap, "Factors Affecting The Current Diffusion of BIM: A Qualitative Study of Online Professional Network," in Creative Construction Conference 2013, Budapest, 2013.

[11] OECD, Oslo Manual: Guidelines for Collecting and Interpreting Innovation Data, 3nd ed., OECD Publishing, European Commision, Eurostat, 2005.

[12] E. S. Slaughter, "Models of construction innovation," Journal of Construction Engineering and Management, vol. 124, no. 3, pp. 226-231, 1998.

[13] E. Rogers, The Diffusion of Innovations, 5th ed. ed., New York: The Free Press, 2003.

[14] "Higher Decision: About the project" [Online]. Available: http://higherdecision.foi.hr/o-projektu," [Accessed 1605 2016.]

[15] M. Urh, G. Vuković, E. Jereb and R. Pintar, "The model for introduction of gamification into e-learning in higher education," Athens, 2015.

[16] B. Divjak and N. Begičević, "Imaginative acquisition of knowledge strategic planning of E-learning," Zagreb, 2006.

[17] H. M. Selim, "Critical success factors for e-learning acceptance: Confirmatory factor models," vol. 49, pp. 396-413, 2007.

[18] N. Begičević, B. Divjak and T. Hunjak, "Prioritization of e-learning form: a multicriteria methodology," Central European Journal of Operations Research,, vol. 15, no. 4, pp. 405-419, 2007.

[19] K. Reddy, BIM for building owners and developers: making a business case for using BIM on projects, John Wiley \& Sons, 2012. 
[20] C. Eastman, P. Teicholz, R. Sacks and K. Liston, BIM Handbook, A Guide to Building Information Modeling for Owners, Managers, Designers, Engineers, and Contractors, 2nd ed., John Wiley \& Sons, Inc, 2011.

[21] C. Lee, "BIM: Changing the Construction Industry," Denver, Colorado, USA, 2008.

[22] BIM Industry Working Group, "A report for the Government Construction Client Group," Department of Business, Innovation and Skills, UK, 2011.

[23] P. v. Both and A. Kindsvater, "Potentials and Barriers for Implementing BIM in the German AEC Market: Results of a Current Market Analysis," in Digital Physicality - Proceedings of the 30th eCAADe Conference Volume 2, Czech Technical University in Prague, 2012.

[24] H. Salleh and W. P. Fung, "Primjena Building Information Modelinga: analiza na osnovi interesnih skupina," Građevinar, vol. 66, no. 8, pp. 705714, 2014.

[25] J. Won, G. Lee, C. Dossick and J. Messner, "Where to Focus for Successful Adoption of Building Information Modeling within Organization," Journal of Construction Engineering and Management, vol. 139, no. 11, pp. 04013014-1 - 04013014-10, 2013.

[26] N. Čuš Babič, P. Podbreznik and D. Rebolj, "Integrating resource production and construction using BIM," Automation in Construction, vol. 19, pp. 539-543, 2010.

[27] B. Cheng, M. Wang, J. Moormann, B. A. Olaniran and N.-S. Chen, "The effects of organizational learning environment factors on e-learning acceptance," Computers \& Education, vol. 58, p. 885-899, 2012.

[28] A. Laan, N. Noorderhaven, H. Voordijk and G. Dewulf, "Building trust in construction partnering projects: An exploratory case-study," Journal of Purchasing \& Supply Management, vol. 17, pp. 95-108, 2011.

[29] M. Bresnena and N. Marshall, "The engineering or evolution of cooperation? A tale of two partnering projects," International Journal of Project Management, vol. 20, pp. 497-505, 2002.

[30] H. C. Linderoth, "Understanding adoption and use of BIM as the creation of actor networks," Automation in Construction, vol. 19, pp. 66-72, 2010.

[31] A. Vishwanath and H. Chen, "Towards a Comprehensive Understanding of the Innovation-Decision Process," in The Diffusion of Innovation: A Communication Science Perspective, A. Vishwanath and G. A. Barnett, Eds., New York, Peter Lang Publishing, 2011, pp. 9-32.

[32] S. Buć and B. Divjak, "Environmental Factors in the Diffusion of Innovation Model: Diffusion of e-learning in a Higher Education 
Institution," in CECIIS 2016, 27th International Conference Proceedings, Varaždin, 2016.

[33] W. M. Cohen and D. A. Levinthal, "Absorptive capacity: a new perspective on learning and innovation," Administrative Science Quarterly, no. 35, p. 128-152, 1990.

[34] S. A. Zahra and G. George, "Absorptive cpacity: a review, reconceptualization, and extension," Academy of Management Review, vol. 27, no. 2, pp. 185-203, 2002.

[35] I. Balaban, E. Mu and B. Divjak, "Development of an electronic Portfolio system success model: An information systems approach," Computers \& Education, vol. 60, p. 396-411, 2013.

[36] M. Buble, Menadžment, Split: Ekonomski fakultet, 2006.

[37] R. F. DeVellis, Scale development: theory and application, London: Sage Publications, 2003.

[38] C. H. Lawshe, "A quantitative approach to content validity," Personnel Psychology, no. 28, pp. 563-575, 1975.

[39] B. H. Hall, "Innovation and diffusion," in The Oxford Handbook of Innovation, Oxford, Oxford University Press, 2013, pp. 459-484.

[40] European Commission, "Europe 2020 Strategy," 2010.

[41] European Commission, "A Digital Agenda for Europe," 2010.

[42] European Commission, "An Agenda for New Skills and Jobs: A European contribution towards full employment," 2010.

[43] European Commission, "A New Skills Agenda for Europe: Working together to strengthen human capital, employability and competitiveness," 2016.

[44] Chen, Y., Dib, H. and Cox, R.F., "A measurement model of building information modelling maturity," Construction Innovation, vol. 14, no. 2, pp. 186-209, 2014.

[45] B. Succar and M. Kassem, "Macro-BIM adoption: Conceptual structures," Automation in Construction, no. 57, p. 64-79, 2015.

[46] A. Matthews, "Working towards a unified approach to BIM in Europe. NBS National BIM Report 2016," RIBA Enterprises, 2016. 